\title{
Rede Brasileira de Bancos de Leite Humano: uma rede baseada na confiança
} Brazilian network of human milk banks: a network based on trust

\section{Red brasileña de bancos de leche humana: una red basada en la confianza}

Mariana Simões Barros ${ }^{1, a}$

marysb@hotmail.com | http://orcid.org/oooo-0003-4782-9425

João Aprígio Guerra de Almeida ${ }^{2, b}$

joaoaprigio@globo.com | http://orcid.org/0000-0003-4605-8876

Alejandro Guillermo Rabuffetti ${ }^{1,0}$

alejandro.pesquisa@gmail.com | http://orcid.org/0000-0001-9328-3588

${ }^{1}$ Fundação Oswaldo Cruz, Instituto de Comunicação e Informação Científica e Tecnológica em Saúde. Rio de Janeiro, $\mathrm{RJ}$, Brasil.

${ }^{2}$ Fundação Oswaldo Cruz, Instituto Nacional de Saúde da Mulher, da Criança e do Adolescente Fernandes Figueira. Rio de Janeiro, RJ, Brasil.

a Doutorado em Informação e Comunicação em Saúde pela Fundação Oswaldo Cruz.

${ }^{\text {b }}$ Doutorado em Saúde da Mulher e da Criança pela Fundação Oswaldo Cruz.

c Mestrado em Saúde Global e Diplomacia da Saúde pela Fundação Oswaldo Cruz.

\section{Resumo}

O estudo que fundamenta este artigo teve como objetivo identificar os vínculos existentes na Rede Brasileira de Bancos de Leite Humano (rBLH-BR). Trata-se de uma pesquisa exploratória-descritiva de natureza qualitativa na qual foram realizadas entrevistas com todos os coordenadores de centros de referência estaduais de bancos de leite humano e com os membros da Comissão Nacional de Bancos de Leite Humano (CNBLH). Os resultados demonstram que o sentimento de pertencimento, ajuda mútua, liberdade para se expressarem e união refletem a confiança na rBLH-BR. Foi verificada a presença de vínculos de associação entre todos os atores da rBLH-BR.

Palavras-chave: Bancos de leite; Confiança; Associação; Leite humano; Informação.

\begin{abstract}
This article bases on a study that aimed to identify the existing links in the rBLH-BR - Rede Brasileira de Bancos de Leite Humano (Brazilian Network of Human Milk Banks). It is an exploratory-descriptive research of qualitative nature where interviews were carried out with all coordinators of state reference centers to human milk banks and with members of the CNBLH - Comissão Nacional de Bancos de Leite Humano (National Commission to Human Milk Banks). The results demonstrate that the sense of belonging, mutual aid, freedom to express themselves and harmony reflect the trust placed in the rBLH-BR. It was verified the presence of association bonds between all actors in the rBLH-BR.
\end{abstract}

Keywords: Milk banks; Trust; Association; Human milk; Information. 


\section{Resumen}

Este artículo es basado en un estudio que tuvo como objetivo identificar los vínculos existentes en la rBLHBR - Rede Brasileira de Bancos de Leite Humano (Red Brasileña de Bancos de Leche Humana). El estudio consistió en una investigación exploratoria-descriptiva de naturaleza cualitativa donde fueron realizadas entrevistas con todos los coordinadores de centros de referencia estatales de bancos de leche humana y con miembros de la CNBLH - Comissão Nacional de Bancos de Leite Humano (Comisión Nacional de Bancos de Leche Humana). Los resultados demuestran que el sentimiento de pertenencia, ayuda mutua, libertad para se expresaren y unión reflejan la confianza en la rBLH-BR. Fue verificada la presencia de vínculos de asociación entre todos los actores de la rBLH-BR.

Palabras clave: Bancos de leche humana; Confianza; Asociación; Leche humana; Información.

Contribuição dos autores:

Concepção e desenho do estudo: Mariana Simões Barros, João Aprígio Guerra de Almeida

Aquisição, análise ou interpretação dos dados: Mariana Simões Barros, João Aprígio Guerra de Almeida e Alejandro Guillermo Rabuffetti. Redação do manuscrito: Mariana Simões Barros.

Revisão crítica do conteúdo intelectual: Mariana Simões Barros, João Aprígio Guerra de Almeida e Alejandro Guillermo Rabuffetti.

Declaração de conflito de interesses: Este trabalho não apresenta conflito de interesses.

Fontes de financiamento: sem financiamento.

Considerações éticas: $\mathrm{O}$ estudo foi submetido ao Comitê de Ética em Pesquisa da Escola Politécnica de Saúde Joaquim Venâncio/ Fiocruz, CAAE: 26858614.8.0000.5241, sendo aprovado pelo mesmo.

Agradecimento/Contribuições adicionais: -

Histórico do artigo: Submetido: 26.jan.2017 | Aceito: 19.mar.2018 | Publicado: 29.jun.2018.

Apresentação anterior: não houve

Licença CC BY-NC atribuição não comercial. Com essa licença é permitido acessar, baixar (download), copiar, imprimir, compartilhar, reutilizar e distribuir os artigos, desde que para uso não comercial e com a citação da fonte, conferindo os devidos créditos de autoria e menção à Reciis. Nesses casos, nenhuma permissão é necessária por parte dos autores ou dos editores. 


\section{Introdução}

Um dos mais graves problemas de saúde pública a ser enfrentado é a morbimortalidade infantil. Estima-se que quatro milhões de bebês no mundo morram a cada ano nas primeiras quatro semanas de vida ${ }^{1}$.

O aleitamento materno é um componente primordial para as estratégias de diminuição da mortalidade neonatal ${ }^{2}$. Além do reconhecimento internacional de que o leite humano (LH) tem a capacidade de reduzir os índices de mortalidade infantil, ele também está associado à prevenção de doenças na fase adulta. A superioridade do aleitamento materno é unanimidade no meio científico ${ }^{3}$.

Os bancos de leite humano (BLH) atuam no Sistema Único de Saúde (SUS) como uma estratégia de qualificação da atenção neonatal no que diz respeito à segurança alimentar e nutricional. Desenvolvendo suas ações na perspectiva do trabalho em rede, os BLHs têm como objetivo a promoção, proteção e apoio ao aleitamento materno, além da coleta, processamento, controle de qualidade e distribuição do leite humano pasteurizado para bebês prematuros, de baixo peso ou hospitalizados em Unidade de Tratamento Intensivo Neonatal. Dessa forma, constituem um elemento estratégico para contribuir com a redução da morbidade e mortalidade infantil, com ênfase no componente neonatal.

O BLH do Instituto Nacional de Saúde da Mulher, Criança e Adolescente Fernandes Figueira (IFF/ Fiocruz) iniciou na década de 1980 uma nova experiência com tecnologias moderadas, adotando novos procedimentos, sobretudo quanto ao processamento e controle de qualidade do LH. Uma segunda etapa consistiu em transformar o BLH/IFF em uma casa a serviço do aleitamento materno, incorporando a promoção, proteção e apoio às suas ações assistenciais. Essa nova forma de atuar rompeu com o paradigma seguido pelo BLH/IFF até aquele momento, ou seja, o de funcionar como ama de leite do século XX, surgindo um novo modelo para os BLHs. Esse modelo, que permite aliar baixo custo operacional ao rigor técnico, capaz de assegurar qualidade ao leite humano coletado, armazenado e distribuído, foi disseminado por todos os BLH no Brasil 4 .

Com a necessidade de abertura de novos bancos de leite no país, surge a preocupação acerca do treinamento dos profissionais e de como difundir os novos conhecimentos gerados. Em consequência, a informação e a comunicação se tornaram algo muito central e estratégico para o crescimento da Rede Brasileira de Bancos de Leite Humano (rBLH-BR)5.

O desenvolvimento da rBLH-BR se baseou em proposições políticas e técnicas com o objetivo de garantir o estabelecimento da maior comunicação entre os BLHs, a partir da interlocução do seu centro de referência nacional com os centros de referência estaduais (CRE), suas comissões técnicas e os BLH locais.

A importância da informação na rBLH-BR é refletida a partir dos encontros dos coordenadores dos centros de referência e dos eventos científicos, como os encontros, seminários e congressos nacionais e internacionais de BLHs. Com o advento da internet, foi criado, em parceria com o Instituto de Comunicação e Informação Científica e Tecnológica da Fiocruz (Icict/Fiocruz), o primeiro site da rBLH-BR, com o intuito de ampliar as oportunidades de acesso ao conhecimento e a informação $0^{6}$.

$\mathrm{O}$ conhecimento gera conectividade à $\mathrm{rBLH}^{6}$. A formação da rede auxilia o estudo dos processos coletivos de produção de conhecimento, a interação e o sistema de posições de atores humanos, não-humanos e suas complexas mediações nas redes sociotécnicas de conhecimentos.

Por ser a Rede Brasileira de Bancos de Leite Humano (rBLH-BR) a maior e mais bem estruturada rede de bancos de leite do mundo7, esta pesquisa se volta para identificar os vínculos formados entre os seus atores. 


\section{Metodologia}

Foi realizada uma pesquisa exploratória-descritiva de natureza qualitativa ${ }^{8}$ com a proposta de identificar os vínculos formados na Rede Brasileira de Bancos de Leite Humano a partir de entrevistas abertas que tiveram o objetivo de explorar a perspectiva informacional das relações nessa rede.

Os critérios para a definição dos níveis de vinculação entre os atores da rBLH-BR foram propostos por Rovere em $2004^{8}$ e a análise das entrevistas foi realizada a partir da técnica de análise de conteúdo na modalidade temática ${ }^{9,10}$.

\section{Níveis de vínculos segundo Rovere}

Rovere $^{11}$ ancora sua proposta de rede aprofundando a ideia de representação da realidade pelos sujeitos. As redes são formadas por pessoas cuja unidade básica de ligação é a relação entre os sujeitos ${ }^{11}$. A partir do momento em que os indivíduos formam redes, constituem laços de solidariedade.

Ao estudar a formação de redes, Rovere ${ }^{11}$ verificou que, durante o processo de construção das redes, diferentes níveis de vínculos se apresentam.

O autor sugere que existem cinco níveis de vínculos na construção de redes, sendo estes denominados de reconhecimento, conhecimento, colaboração, cooperação e associação (Quadro 1). Cada um desses níveis contribui para o próximo. O conhecimento dos níveis permite ajudar a organizar, analisar e monitorar os graus de profundidade e consistência de uma rede.

O primeiro nível, reconhecimento, expressa o valor da aceitação do outro, ou seja, é a ação de reconhecer e aceitar a existência do outro ou, mais precisamente, que o outro tenha o direito de existir.

Após o reconhecimento de que o outro existe, é necessário conhecer o outro e, por isso, o segundo nível é o conhecimento. Ao considerar o outro como par e aceitá-lo como um interlocutor válido, emerge o interesse e a necessidade de conhecer o que ele tem de diferente que o faz não ser um igual.

O terceiro nível parte de casos esporádicos de colaboração espontânea e voluntária. O nível de colaboração envolve a troca de experiências e vivências recíprocas ${ }^{11}$.

O quarto nível é denominado cooperação, ou seja, operação em conjunto. Para isso, é necessário que haja um problema em comum (uma co-problematização), o que leva à construção de solidariedade.

O quinto e último nível é aquele em que há associação, ou seja, há parceria e existe alguma forma de contrato ou acordo que consiste não só em compartilhar recursos e/ou atividades, mas em estabelecer objetivos e projetos comuns. Um nível de vínculo desta natureza vai requerer e, ao mesmo tempo, gerar confiança, que é normalmente uma expectativa forte numa rede, e pode ser pensado mais como ponto de chegada do que ponto de partida 9 .

Caso haja convivência e compartilhamento de recursos, pode haver compartilhamento de projetos e, diante de um projeto, cada pessoa, instância ou instituição pode se articular mais facilmente com a outra.

Quadro 1 - Níveis de profundidade de vínculos para a construção de redes, segundo Rovere

\begin{tabular}{|l|l|l|}
\hline Nível & Ações & Valor \\
\hline 5. Associar-se & Compartilhar objetivos e projetos & Confiança \\
\hline 4. Cooperar & Compartilhar atividades e/ou recursos & Solidariedade \\
\hline 3. Colaborar & Prestar ajuda esporádica & Reciprocidade \\
\hline 2. Conhecer & Conhecimento do que o outro é ou faz & Interesse \\
\hline 1. Reconhecer & Destinadas a reconhecer que o outro existe & Aceitação \\
\hline
\end{tabular}

Fonte: Rovere (1999, p. 25). 


\section{Procedimentos metodológicos}

A técnica de entrevista não estruturada, ou aberta, foi utilizada para a exploração das questões relacionadas à interação entre atores individuais e institucionais que participam da rBLH.

Em relação à sua estruturação, o entrevistador introduziu o tema e o entrevistado teve a liberdade para discorrer sobre o assunto.

A entrevista não estruturada pode ser utilizada quando se deseja obter o detalhamento do maior número possível de informações sobre determinado tema na perspectiva do entrevistado ${ }^{12,13}$.

Todos os procedimentos de coleta de dados foram realizados pela pesquisadora principal. As entrevistas foram realizadas de forma individual.

O termo de consentimento livre e esclarecido foi apresentado ao primeiro contato com cada informantechave, sendo o seu preenchimento e a sua assinatura pré-requisito para a entrevista. Todos os entrevistados foram notificados da utilização das informações geradas para a composição deste trabalho.

Foram entrevistados 31 atores, sendo eles todos os coordenadores dos centros de referência estaduais e todos os membros da Comissão Nacional de Bancos de Leite Humano (CNBLH). Alguns entrevistados exerciam as duas funções.

As entrevistas foram realizadas entre os dias 16 de outubro de 2014 e 7 de novembro de 2014. Do total de entrevistados, trinta eram do sexo feminino e somente um do sexo masculino. A idade dos participantes e o tempo na função não foram considerados como pontos de corte para este estudo.

\section{Resultados e discussão}

A trajetória da rBLH-BR aponta para a solidificação de uma rede que atualmente compartilha objetivos e projetos.

Buscou-se identificar no conteúdo dos depoimentos dos atores, núcleos que conferem sentido ao tipo de vínculo. Como dito anteriormente, é a teoria de Rovere ${ }^{11}$ que serve de aporte conceitual analítico para identificação dos vínculos gerados na formação de redes.

Para esse autor, o nível de associação se refere à ação de desenvolvimentos de projetos comuns, em um contexto no qual o valor confiança é pré-requisito e produto. O nível de cooperação está associado à ação de compartilhar atividades e/ou recursos, o de colaboração à ação de prestar ajuda esporádica, conforme se vê no Quadro 1.

Ao analisar individualmente as falas dos atores entrevistados, fica evidenciado o vínculo de associação que cada um deles mantém com a rBLH-BR.

O ensino, de acordo com a Resolução da Diretoria Colegiada (RDC) $n^{0} 171 / 2006^{14}$, é um projeto compartilhado pela rede, já que os centros de referência estaduais são responsáveis pela educação permanente e continuada dos profissionais da rede. Todos os funcionários que trabalham em bancos de leite humano (BLH) e postos de coleta de leite humano (PCLH) devem ser certificados de acordo com os critérios estabelecidos pelo Conselho Regional de Nutricionistas (CRN).

As falas dos entrevistados corroboram a afirmação de que o ensino é compartilhado pelos atores da rede, e não é somente uma atividade, tendo em vista a sua importância como elemento prioritário para a consolidação da rBLH-BR ${ }^{15}$.

"A gente tá sempre capacitando a equipe [...]. Então a gente faz junto com o grupo, esses [cursos] macrorregionais.” (Fala do entrevistado A-119).

"Eu sempre colaboro com essas iniciativas de fazer esses cursos. Estar ministrando e capacitando o pessoal de lá.” (Fala do entrevistado A-87). 
"Eu dei um curso a um banco de leite há algumas semanas.” (Fala do entrevistado A-4).

"Me sinto agraciada por ser tutora." (Fala do entrevistado A-121).

As ações da rBLH-BR são capilarizadas pelos CRE, que as levam aos BLHs dos diferentes municípios ${ }^{14}$. Dessa forma, os CRE atuam como apoio e ajudam os BLHs na resolução dos problemas que emergem no seu cotidiano, tanto de ordem política como técnica.

Essa ajuda aparece como algo permanente, demonstrando não só a solidariedade entre os atores, mas também a confiança estabelecida.

"Eu acho que eu agreguei valor. Acho que eu estou conseguindo ajudar os bancos de leite a se sentirem mais fortes, mais presentes nessa rede. Porque todos nós fazemos parte da rede brasileira. Então eu sinto que tenho um papel importante também nessa rede pra ajudá-la a crescer no meu estado. Acho que sou uma referência para os outros bancos." (Fala do entrevistado A-6).

"Nunca deixei de atender uma solicitação de um banco." (Fala do entrevistado A-4).

"Sempre ouço, sempre falo. Se eles pedem, eu tento atender prontamente, então me acho bem ativa na rede." (Fala do entrevistado A-2).

[sobre a participação na rede] "Fazer os bancos de leite seguirem realmente todas as normativas [...]. Fazer o estado [do entrevistado] aparecer dentro dessa rede brasileira. Na minha região ajudamos dois bancos de leite que estavam com bastante dificuldade, né? Nós fizemos tanto pressão política como demos um suporte técnico mesmo." (Fala do entrevistado A-5).

A ajuda dos CRE dada aos BLH nos municípios os levam a ter confiança para perguntar.

"As pessoas que trabalham em outros bancos e têm a confiança de chegar pra você e perguntar, de questionar alguma coisa, então é uma relação de confiança." (Fala do entrevistado A-1).

Essa ajuda se mostra contínua e se configura como troca bilateral, não como obrigação, mas como solidariedade baseada em confiança.

"Cada um procura ajudar o outro. Olha, eu consegui fazer isso. Tem a questão da implantação do o8oo esse ano, eu mandei toda a estruturação pra uma coordenadora para ela poder lançar durante a semana mundial, [...] pra parceira com o "Bombeiro amigo do peito", mandei pra colega, ela também já me mandou para um projeto de lei." (Fala do entrevistado A-139).

"O apoio é fundamental pra você conseguir tomadas de decisões. Embasamento científico-teórico, isso traz credibilidade para todos os seus processos. Você consegue ser melhor aceito na comunidade, e o reconhecimento vem mais rápido também. Você tem uma solução, você vai compartilhar com o outro, você vai trocar experiências e com isso todo mundo vai ganhar." (Fala do entrevistado A-3).

Um fator que chama a atenção ao remeter à associação entre os atores da rBLH BR, e que esteve muito presente nas falas dos entrevistados, foi a confiança dos CRE e da CN de poder contar com o suporte do CRN e de que, caso necessitem, terão ajuda do mesmo.

"Recebo ajuda de todos os tipos, para esclarecimento de dúvidas, ajuda financeira para me deslocar e estar recebendo essas informações, apoio emocional. Recebo apoio de todo jeito [..]. Quando você tem uma equipe, um grupo por trás facilita." (Fala do entrevistado A-69).

"E eles [CRN] estão sempre tentando ajudar. Sempre tentando dar uma solução, te ajudando a encontrar." (Fala do entrevistado A-87). 
"Quando a gente precisa, eles [CRN] estão ali disponíveis, respondem, nos dão o suporte." (Fala do entrevistado A-5).

"Eu sinto que eles [CRN] também criaram comigo, assim, uma relação de confiança, de parceria, né? [...] tem esse reconhecimento de perguntar para referência, para a gente poder ter mais essa ajuda mais direta." (Fala do entrevistado A-70).

Essa confiança de que será ajudado caso necessite se estende a toda a Rede.

"Eu acho assim, a primeira coisa é você ter o norteamento de que todo mundo faz o mesmo trabalho. Alguns com um aspecto maior ou menor do que os outros. Mas o trabalho em si é realizado por todos. O meu banco de leite está inserido dentro de uma UTI [Unidade de Terapia Intensiva] neonatal que tem 19 leitos. Isso é importante dentro [do estado do entrevistado], é uma unidade que precisa. É um banco muito novo. O banco de leite só tem quatro anos. Ele não tem uma grande expressão ainda dentro da sua história, mas ele já foi criado com esse sentimento de rede. Com o sentimento de se você tiver leite sobrando você vai dar para o banco de lá, que o banco de lá está precisando. Se você precisar, você pode ligar para o fulano que o fulano vai te ajudar. Ele já nasceu dentro desse sentimento de rede." (Fala do entrevistado A-31).

"Eu tenho certeza que, se eu precisar, eu recebo ajuda sim.” (Fala do entrevistado A-137)

O fato de a rBLH-BR valorizar internamente os integrantes, fazendo com que se sintam importantes, também tem relação com a confiança que a permeia.

\begin{abstract}
"Acho que a união do grupo faz se sentir valorizada. Você se sentir importante. Uma coisa que tudo o que vocêfala em reuniões, tanto por videoconferências como presenciais, você se sente valorizada, sempre lisonjeada, porque sempre tem uma maneira das pessoas te elogiarem. O grupo da referência nacional sempre te elogia e traz aquilo de "eu sou importante", entendeu?" (Fala do entrevistado A-2).

“A rede é uma das que mais reconhece o nosso trabalho." (Fala do entrevistado A-3).

"Me vejo como multiplicadora e é uma honra fazer parte desse trabalho; a gente vê que não só lhe repassam trabalho, mas te valorizam como funcionário, como pessoa, então você tem como mensurar isso. Isso é legal." (Fala do entrevistado A-140).

"Eu até brinco, toda vez que eu volto de um encontro, eu volto revigorada. Você vê que não é só você quem passa por isso, os outros também. Eu me sinto muito acolhida. Eu adoro cada um." (Fala do entrevistado A-87).
\end{abstract}

Através das falas dos entrevistados foi possível perceber que há sentimento de união e acolhimento entre os atores da rBLH-BR.

"É um trabalho de construção coletiva, né? Então acho assim, que tô ali tô atuando, tô com os bancos. Você pensa na palavra construção coletiva, você tá inserida todo o tempo num grupo. Você faz parte de uma rede. Você faz parte de um grupo [...] pelo acolhimento do grupo, pela união do grupo, uma pessoa ajudando as outras. É o tempo todo isso, a gente sente nas falas, no abraço, você sente confiança, você se sente [...]." (Fala do entrevistado A-2).

"Me sinto acolhida por fazer parte da equipe. A rede tem a visão de construção coletiva. E dentro dessa coletividade tem o acolhimento. Como eu disse, em relação a qualquer momento, se você ligar como banco de leite, você é acolhido por qualquer um. Em uma ligação você percebe o acolhimento de quem está lhe atendendo." (Fala do entrevistado A-121).

Teixeira ${ }^{16}$ relaciona a comunicação como ferramenta para o acolhimento. Ao ter o sistema de saúde como campo, o autor aponta quão fundamental é o papel das conversas entre os atores para o estabelecimento de vínculos.

Da mesma maneira, a união entre os atores da rBLH-BR é alcançada a partir do diálogo, em que a liberdade para se expressar se apresenta como um diferencial dessa rede. 
"No trabalho de rede, de agregar seres, de me aproximar mais do sistema de gestão maior, local, isso tem dado resposta imediata para a gente. Eu observo isso [...]. Assim, é uma militância, quem se encontra na rede adquire assim, um grau de afetividade pelo trabalho e acho que isso tem uma relação muito grande com a forma de condução que eles utilizam. Você realmente se sente em casa. Eu não me sinto inibida. Essa questão de você garantir espaço pra fala, acho que é um grande diferencial." (Fala do entrevistado A-120).

"Que ninguém tá aqui pra ser o dono do saber, porque o tempo todo é dito o seguinte: que todo mundo tem algo pra contribuir, que a rede quer ouvir todo mundo, a rede quer ver o que todo mundo pensa." (Fala do entrevistado A-85).

“As pessoas aqui são muito abertas, as pessoas dão espaço.” (Fala do entrevistado A-119).

A liberdade para se expressar vai além do ouvir, na medida em que os atores se percebem participantes dos processos de construção da rBLH-BR através do compartilhamento das decisões.

"Ser chamada pra tomar essas decisões como na reunião de hoje, em que as decisões não são impostas, elas são compartilhadas e a gente se sente valorizada porque a gente participa da construção disso." (Fala do entrevistado A-136).

"Eu acho que é a questão da confiabilidade [...]. Você faz, faz a execução, e você tem o livre acesso de ir e vir. É esse ir e vir que é importante, que te fortalece [...]. Então é a viabilidade e confiabilidade mesmo no trabalho, essa troca mútua, a participação, sinto." (Fala do entrevistado A-140).

A satisfação de pertencer a essa rede faz com que alguns entrevistados a tenham associado a uma família, ou um time, em que todos compartilham projetos e se apoiam.

"Acho eles [outros atores da rBLH-BR] assim, amigos, irmãos mesmo. Eu me sinto feliz. Quando falo, falo com todos com carinho, quando ligo, norte e sul, do Oiapoque ao Chuí." (Fala do entrevistado A-116).

"Isso é uma família, apesar de a gente sempre ter encontros periódicos, a gente sempre se liga, conversa [...] faz a ligação e a gente é atendido, né? O contato, a ligação [...].” (Fala do entrevistado A-135).

O amor ao trabalho realizado se traduziu na dedicação perante as ações em torno da rede, e alguns entrevistados relataram que já dispuseram de recursos próprios para realizarem visita a outros bancos de leite humano a fim de manter a coesão da rBLH-BR.

"Eu visitei todos os bancos do estado, eu fui do norte ao sul, do leste ao oeste do estado, visitar banco a banco, foi uma parceria com eles, eu ia para um determinado local às minhas custas, e de lá eles me levavam para o próximo, inclusive numa tentativa de manter a coesão, de melhorar as condições do trabalho dos bancos." (Fala do entrevistado A-4).

"Não tenho vontade de me aposentar porque eu gosto muito do que eu faço, então, fazendo a coisa com amor, não pesa, né?" (Fala do entrevistado A-69).

“Às vezes, já fui a bancos pela minha conta [...]. Eu nunca me nego a uma demanda que chega e eu tento sempre cumprir e cumprir do jeito que aprendi." (Fala do entrevistado A-118).

A confiança na rBLH-BR é expressa pelo orgulho relatado por alguns entrevistados de fazerem parte dessa rede.

“Me sinto muito lisonjeada de fazer parte dessa rede.” (Fala do entrevistado A-123).

“Acho que sinto orgulho pessoal de um trabalho bem-sucedido.”(Fala do entrevistado A-31). 


\section{Conclusões}

Este estudo possibilitou ampliar a compreensão acerca dos vínculos formados entre os atores da Rede Brasileira de Bancos de Leite Humano.

Foi possível identificar que o ensino é um projeto estratégico compartilhado pelos atores dessa rede. E que o sentimento de pertencimento, ajuda mútua, solidariedade, liberdade para se expressar e união refletem a confiança na rBLH-BR.

Contudo, há de se considerar que neste estudo foram entrevistados somente os coordenadores de centros de referência estaduais e membros da Comissão Nacional de Bancos de Leite Humano.

O trabalho sugere que os resultados alcançados pela rBLH-BR mantêm relação direta com o nível de vinculação entre os atores que a integram. Nesse sentido, verificou-se a existência de vínculos de associação alicerçados na confiança depositada na rede.

Entendemos que o projeto traz uma importante contribuição para a construção de um modelo de gestão que considere e valorize os elementos que fortalecem a formação de vínculos.

\section{Referências}

1. Lawn JE, Cousens S, Zupan J; 4 million neonatal deaths: When? Where? Why? Lancet. 2005 Mar 5-11;365(9462):891-900. doi: https://doi.org/10.1016/S0140-6736(05)71048-5

2. Jones G, Steketee RW, Black RE, Bhutta ZA, Morris SS, Bellagio. How many deaths can we prevent this year? Lancet. 2003 Jul;362(9377):65-71. doi: https://doi.org/10.1016/S0140-6736(03)13811-1

3. Almeida JAG, Novak FR. Amamentação: um híbrido natureza-cultura. J Pediatr (RJ). 2004;80(5 Supl):S119-S125. doi: http://dx.doi.org/10.1590/S0021-75572004000700002

4. Novak FR, Almeida JAG. Alternative test for detection of coliforms bacteria in manually expressed human milk. J Pediatr (RJ). 2002;78:193-6. doi: http://dx.doi.org/10.1590/S0021-75572002000300005

5. Maia PRS, Almeida JAG, Novak FR, Silva DA. Rede Nacional de Bancos de Leite Humano: gênese e evolução. Rev Bras Saúde Matern Infant. 2006 set.;6(3):285-92. doi: http://dx.doi.org/10.1590/S1519$\underline{38292006000300004}$

6. Maia PRS. Geração, difusão e apropriação do conhecimento na Rede Nacional de Bancos de Leite Humano [Tese]. Rio de Janeiro: Instituto Fernandes Figueira, Fundação Oswaldo Cruz; 2004.

7. Giugliani ERJ. Rede Nacional de Bancos de Leite Humano do Brasil: tecnologia para exportar. J Pediatr (RJ). 2002;78:183-4. doi: http://dx.doi.org/10.1590/S0021-75572002000300001

8. Rovere M. Algunas sugerencias para el desarrollo futuro de la Red de Investigación en Sistemas y Servicios de Salud en el Cono Sur de América Latina [Internet]. Córdoba; 2004. [citado 2014 abr. 5]. Disponível em: http://www.medicinafamiliar.fcm.unc.edu.ar/actividades/cursopami/7-redes.pdf

9. Deslandes, RG, Gomes R, Minayo MCS, organizadora. Pesquisa social: teoria, método e criatividade. 29. ed. Petrópolis, RJ: Vozes; 2010.

10. Bardin L. Análise de conteúdo. 3 ed. Lisboa: Edições 70; 2004.

11. Rovere M. Redes en salud; un nuevo paradigma para el abordaje de las organizaciones y la comunidad [Internet]. Rosario: Ed. Secretaría de Salud Pública/AMR, Instituto Lazarte; 1999 [citado 2018 mayo 07]. Disponible en: https://goo.gl/EMVw6d

12. Minayo MCS. O desafio do conhecimento: pesquisa qualitativa em saúde. São Paulo: Hucitec;1993.

13. Gil AC. Como elaborar projetos de pesquisa. 4 ed. São Paulo: Atlas; 2009.

14. Ministério da Saúde (BR). Agência Nacional de Vigilância Sanitária. Resolução RDC no 171, de 04 de setembro de 2006. Dispõe sobre o Regulamento Técnico para o funcionamento de Bancos de Leite Humano. DOU, Seção 1, p. 33. 2006 set. 05.

15. Almeida JAG. Amamentação: um híbrido natureza-cultura. Rio de Janeiro: Editora Fiocruz; 1999.

16. Teixeira RR. O acolhimento num serviço de saúde entendido como uma rede de conversações [Internet]. In: Pinheiro R, Mattos RA. Construção da integralidade: cotidiano, saberes e práticas em saúde. Rio de Janeiro: IMS, ABRASCO, 2003. [citado 2015 mar. 06] p. 89-111. Disponível em: http://www.corposem. org/rizoma/acolhiconversa.htm 